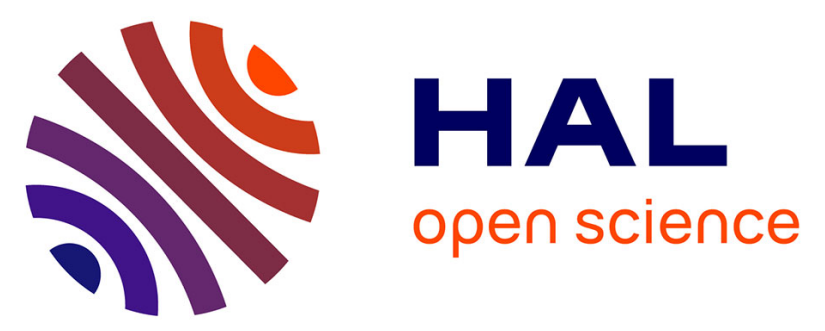

\title{
Prenatal and childhood exposure to chlordecone and sex-typed toy preference of 7-year-old Guadeloupean children
}

Sylvaine Cordier, Nadine Forget-Dubois, Mireille Desrochers-Couture, Florence Rouget, Leah Michineau, Christine Monfort, Jean Pierre Thome, Philippe Kadhel, Luc Multigner, Gina Muckle

\section{To cite this version:}

Sylvaine Cordier, Nadine Forget-Dubois, Mireille Desrochers-Couture, Florence Rouget, Leah Michineau, et al.. Prenatal and childhood exposure to chlordecone and sex-typed toy preference of 7-year-old Guadeloupean children. Environmental Science and Pollution Research, 2020, 27 (33), pp.40971-40979. 10.1007/s11356-019-05686-x . hal-02179393

\section{HAL Id: hal-02179393}

https://hal-univ-rennes1.archives-ouvertes.fr/hal-02179393

Submitted on 17 Oct 2019

HAL is a multi-disciplinary open access archive for the deposit and dissemination of scientific research documents, whether they are published or not. The documents may come from teaching and research institutions in France or abroad, or from public or private research centers.
L'archive ouverte pluridisciplinaire HAL, est destinée au dépôt et à la diffusion de documents scientifiques de niveau recherche, publiés ou non, émanant des établissements d'enseignement et de recherche français ou étrangers, des laboratoires publics ou privés. 
TITLE

Prenatal and childhood exposure to chlordecone and sex-typed toy preference of 7-year-old Guadeloupean children

\section{AUTHORS}

Sylvaine CORDIER ${ }^{1, *}$, Nadine FORGET-DUBOIS ${ }^{2}$, Mireille DESROCHERS-COUTURE ${ }^{2}$, Florence

ROUGET $^{3}$, Leah MICHINEAU ${ }^{1}$, Christine MONFORT ${ }^{1}$, Jean Pierre THOME ${ }^{4}$, Philippe KADHEL ${ }^{5}$ Luc MULTIGNER $^{1}$, and Gina MUCKLE ${ }^{2}$

${ }^{1}$ Univ Rennes, Inserm, EHESP, Irset (Institut de recherche en santé, environnement et travail) - UMR_S 1085, F35000 Rennes, France.

${ }^{2}$ Centre de recherche du CHU de Québec-Université Laval and École de psychologie, Université Laval, Québec, Canada

${ }^{3}$ CHU de Rennes, Univ Rennes, Inserm, EHESP, Irset (Institut de recherche en santé, environnement et travail) UMR_S 1085, F-35000 Rennes, France

${ }^{4}$ Université de Liège, LEAE-CART (Laboratoire d'Ecologie Animale et d'Ecotoxicologie-Centre de Recherche Analytique et Technologique), B- 4000 Liège, Belgium.

${ }^{5} \mathrm{CHU}$ de Pointe-à-Pitre, Univ Antilles, Univ Rennes, Inserm, EHESP, Irset (Institut de recherche en santé, environnement et travail) - UMR_S 1085, F-97110 Pointe-à-Pitre, France.

* Corresponding author. Email: Sylvaine.cordier@inserm.fr. Tel: +33223235929

Key words: child development, sex-typed play behavior, chlordecone, endocrine-disrupting chemicals, French West Indies, insecticides, organochlorine

Acknowledgments: We thank Pierrich Plusquellec for his help in the design of the play situation. This work was supported by grants from the French General Health Directorate (DGS RMC11129NNA). 


\begin{abstract}
Chlordecone was used intensively as an insecticide in the French West Indies. Because of its high persistence, the resulting contamination of food and water has led to chronic exposure of the general population as evidenced by its presence in the blood of people of Guadeloupe, in particular in pregnant women and newborns, and in maternal breast milk. Chlordecone is recognized as a reproductive and developmental toxicant, is neurotoxic and carcinogenic in rodents, and considered as an endocrine-disrupting compound with well-established estrogenic and progestogenic properties both in vitro and in vivo. The question arises of its potential consequences on child neurodevelopment following prenatal and childhood exposure, in particular on behavioral sexual dimorphism in childhood.
\end{abstract}

We followed 116 children from the TIMOUN mother-child cohort study in Guadeloupe, who were examined at age 7 . These children were invited to participate in a seven-minute structured play session in which they could choose between different toys considered as feminine, masculine or neutral. The play session was video recorded, and the percentage of the time spent playing with feminine or masculine toys was calculated. We estimated associations between playtime and prenatal exposure to chlordecone (assessed by concentration in cord blood) or childhood exposure (determined from concentrations in child blood obtained at the 7-year followup), taking into account confounders and co-exposures to other environmental chemicals. We used a two-group regression model to take into account sex differences in play behavior. Our results do not indicate any modification in sex-typed toy preference among 7-year old children in relation with either prenatal or childhood exposure to chlordecone. 


\section{Introduction}

Sexual differentiation of brain starts during fetal development under the parallel influence of sex hormones and sex chromosomes (McCarthy et al. 2011; Lombardo et al. 2012). Expression of this differentiation includes both reproductive and non-reproductive behaviors that show sex differences. One of its first manifestation is observed early during childhood as toy preference (females choose dolls, males prefer toy-cars and balls), and this is observed among both human (Alexander et al. 2009) and monkey offspring (Hasset et al. 2008). Compared to other behavioral sex differences such as aggression level, childhood play behavior gives the strongest evidence for an influence of steroid hormones during early fetal life (Collaer et al. 1995). An argument against the role of social influence in this sex-typed behavior can be drawn from studies of individuals who have experienced abnormal gonadal exposure but normal socialisation. Nordenström et al. (2002), for instance, reported that girls with congenital adrenal hyperplasia, a syndrome resulting in overproduction of adrenal androgens from early fetal life, showed a preference for masculine toys in a structured play situation, and a dose-response relationship between the degree of preference and disease severity.

Endocrine-disrupting chemicals (EDCs), environmental chemicals that perturb hormonal systems, may interfere with normal brain foetal development when exposure occurs during pregnancy, including its sexual differentiation (Frye et al. 2012). A number of studies have been conducted on the association between perinatal exposure to some EDCs and sexual dimorphic neurobehaviors. Some individual congeners of polychlorinated biphenyls (PCBs), a large class of persistent contaminants, are known for their neurotoxic effects in animals and humans (Faroon et al. 2000), and for their ability to disrupt steroid hormone signalling via estrogen or aryl hydrocarbon receptors (Bell 2014). Sexually dimorphic neurobehaviors following perinatal exposure to selected PCBs were reported in animals (Schantz et al. 1995) and humans in the Yu-Cheng cohort of children born to mothers accidentally exposed to high levels of PCBs and dioxins in rice oil in Japan and Taiwan (Guo et al. 1995). Using the Pre-School Activities Inventory (PSAI) to rate sexually dimorphic patterns of play behavior in school-age children, Vreugdenhill et al. (2002) and Winneke et al. (2014) reported similar associations: a masculinization of typical sex play behavior in girls as well as a feminization of typical sex play behavior in boys with increasing prenatal exposures to PCBs and dioxins. A similar alteration of sex-typed behaviors in boys using the PSAI was reported in relation with prenatal exposure to phthalates, a category of EDCs with antiandrogenic properties (Swan et al. 2010).

Chlordecone (Kepone) is a synthetic organochlorine compound, a recognized reproductive and 
developmental toxicant, neurotoxic and carcinogenic in rodents (Faroon et al. 1995). Chlordecone is an EDC with well-established estrogenic and progestogenic properties both in vitro and in vivo (Hammond et al. 1979; Lemaire et al. 2006; Scippo et al. 2004; Vonier et al. 1996). The toxicity of chlordecone to humans was revealed following intoxication of workers in a production facility in Hopewell, Virginia, USA in the 1970s. Intoxicated workers showed reduced fertility and signs of neurotoxicity such as tremors and memory loss (Cannon et al. 1978). Experimental studies with rodents have shown that gestational and perinatal chlordecone exposure impairs neurobehavior (acquisition and retention of active and passive avoidance response, acoustic startle reflex, motor coordination) during pre-weaning and post-weaning development (Mactutus and Tilson 1985; Mactutus and Tilson 1984; Mactutus et al. 1982; Squibb and Tilson 1982). Such alterations appear generally more pronounced in males, suggesting sex-dependent neurotoxic effects. Chlordecone exposure during the sensitive period for neurodevelopment can affect sexual differentiation of the brain, resulting in significant permanent sexually differentiated behaviors in adult rats (Laessig et al. 2007).

Chlordecone was intensively used as an insecticide in the French West Indies from 1973 to 1993 to control banana root borers. This pesticide undergoes no significant biotic or abiotic degradation in the environment and, as a consequence, permanently polluted soils and waters led to contamination of foodstuffs. It was only from 1999 that French authorities became aware of the extent of this pollution (Dubuisson et al 2007; Guldner et al. 2010; Seurin et al. 2012). The first population contamination data are from the early 2000s and were in the ppb range ( $\mu \mathrm{g} / \mathrm{L}$ wet weight) in blood and milk (Multigner et al. 2016). There is evidence that chlordecone is still present in the blood of the general population of Guadeloupe, in particular in pregnant women and newborns, and in maternal breast milk (Guldner et al. 2010; Dallaire et al. 2012). To evaluate the possible health effects resulting from exposure to chlordecone during pregnancy and childhood, we implemented a mother-child cohort in Guadeloupe (TIMOUN cohort) from 2004. We reported in follow-up conducted during infancy significant associations between cord chlordecone concentrations and poorer neurodevelopmental outcomes, more precisely with reduced novelty preference at 7 months (above $0.31 \mu \mathrm{g} / \mathrm{L}$ in cord blood) (Dallaire et al. 2012) and poorer fine motor development at 7 (above $0.06 \mu \mathrm{g} / \mathrm{L}$ in cord blood) and 18 months (above $0.24 \mu \mathrm{g} / \mathrm{L}$ in cord blood), age at which only males were affected (Boucher et al. 2013).

Here we report the evaluation of sex-typed play behavior of 7-year-old children in the TIMOUN cohort, in relation with prenatal and childhood exposure to chlordecone. 


\section{Methods \\ Population and data collection}

The TIMOUN study is a prospective mother-child cohort currently underway in the Guadeloupe archipelago. Between November 2004 and December 2007, 1068 pregnant women were enrolled during their late prenatal visit at the public hospitals of Pointe-à-Pitre or Basse-Terre or at a local antenatal care dispensary. A prenatal maternal face-to-face interview was conducted at enrollment by trained midwives to assess obstetrical, medical, personal, and socioeconomic characteristics. Maternal diseases, adverse delivery incidents, as well as newborn anthropometric parameters and health information, were collected from child and maternal medical records.

For assessment of child neurodevelopment at 3, 7 or 18 months, a subsample was selected. Exclusion criteria associated with maternal diseases were history of diabetes, gestational diabetes mellitus, hypertension, epilepsy, human immunodeficiency virus infection, and long-term corticotherapy $(n=254)$. Exclusion criteria for newborns $(n=225)$ were multiple birth, stillbirth, major birth defects, gestational age $<37$ wks, APGAR $<7$ at $5 \mathrm{~min}$, intrauterine growth restriction $<10^{\text {th }}$ percentile of birth weight for gestational age, severe respiratory distress, severe icterus, hypoglycemia and maternofoetal infection. For the remaining 589 participants, 287 were not contacted because of incorrect address or refusal to participate. Altogether, 302 children participated in at least one follow-up at 3, 7 or 18 months of age (Dallaire et al. 2012; Boucher et al. 2013). Of the 302 children, 70 did not have a cord blood sample. At the 7-year follow-up, 62 were not contacted because of incorrect address or for exceeding the age window, and 15 refused; 155 came at the Pointe-à-Pitre hospital for neuropsychological and medical evaluation and collection of a blood sample, 125 of them completed a play session as part of the neuropsychological evaluation. Lack of access to the playroom because of other activities was the main reason for the missing play session for 30 children.

A maternal interview was conducted to provide information on familial environment of the child at the 7-year follow-up, and to document the non-verbal intellectual functioning of the mother assessed with the Raven's Progressive Matrices continuous score (Raven et al. 2003). Additionally, at the 7 and 18 months followed-ups, the Home Observation for Measurement of the Environment (HOME, Caldwell et al. 2001) was used to document the quality of stimulation received by the child.

Written informed consent was obtained from the principal caregiver, usually the mother, of each participating child. The research procedures were approved by the Guadeloupean Ethics Committee for biomedical studies involving human subjects. 
Assessment of sex-typed play behavior was organized in a room dedicated to this task, as a structured toy session (Nordenström et al. 2002). Seven different toys chosen as typically masculine, feminine or neutral for children of that age, were placed in a defined order in a semi-circle on a carpet, every other toy being masculine and feminine and the neutral toys in between. Feminine toys included a doll with a blanket and a bottle, a female doll's head with a comb, a brush and colored hairpins and elastics, and a set comprised of a pink pony camper with 3 small colored ponies and a bucket. Masculine toys were a set of 5 miniature cars, a set composed of a fire truck and an helicopter with two figurines, and a set of two superheroes figurines with their accessories. Neutral toys were a set of 3 children's books. The child tester instructed the child to sit in the middle of the carpet and play with the toys until her return. The playing time was videotaped for a total of $7 \mathrm{~min}$. The classification of either feminine, masculine or neutral play was done according to which toy was touched by the child. Instances where children played with toys of two categories at the time were counted separately from masculine, feminine or neutral play. Two examiners unaware of the child exposure did the coding. A between-rater agreement was established first, and then calculated every 10 videos to maintain it. The raters were unaware of which videos would be used for this purpose. Agreement on a play sequence duration was considered acceptable if the durations observed by the two raters differed by $5 \%$ or less. Feminine and masculine play are reported as a proportion of the complete playing time. We realized during training of video coding that even though the pony camper was considered a feminine toy, the boys played with it as with a big truck, considerably more than with any other feminine toy. We therefore counted the time allotted to playing with the pony camper separately and removed it from feminine playtime for all participants. We kept in the analyses only the participants whose total playtime was at least 3 minutes after removal of the pony camper sequences $(\mathrm{N}=116)$.

\section{Assessment of exposure to contaminants and nutrients}

A cord blood sample, and a child blood sample at the 7 years visit, were collected in EDTA tubes to document respectively prenatal and childhood exposure to chlordecone and to other environmental contaminants. Plasma samples were stored at $-30{ }^{\circ} \mathrm{C}$ in Polypropylene Nunc ${ }^{\circledR}$ tubes following centrifugation. Chlordecone, p,p'dichlorodiphenylchloroethylene (DDE), PCB congener 153 (PCB-153) and lipids were measured in plasma. Total mercury $(\mathrm{Hg})$ and lead $(\mathrm{Pb})$ were quantified in whole blood. Determination of chlordecone, DDE and PCB-153 concentrations were done by the Center for Analytical and Research Technology at Liege University (Belgium). Contaminant concentrations were analyzed by high-resolution gas chromatography (Thermo Quest 
Trace 2000). Preparation of samples and quantification method were previously described (Debier et al. 2003; Multigner et al. 2010). The limit of detection (LOD) was $0.05 \mu \mathrm{g} / \mathrm{L}$ for the cord chlordecone blood measures and $0.02 \mu \mathrm{g} / \mathrm{L}$ for the childhood chlordecone measures, and $0.05 \mu \mathrm{g} / \mathrm{L}$ for all measures of PCB-153 and DDE. Values under the LOD were replaced by random values $<$ LOD with the R package RobCompositions (Templ et al. 2011) for the cord and child chlordecone, cord and child PCB-153 and cord DDE measures; child DDE had only one value under LOD, which was kept as measured. Total cholesterol and triglyceride in plasma were determined by standard enzymatic procedures (DiaSys Diagnostic Systems GmbH; Holzheim, Germany), and total lipid concentrations were calculated as described by Bernert et al. (2007). Blood $\mathrm{Hg}$ and Pb concentrations were measured by inductively coupled plasma mass spectrometry (ICP-MS) at the laboratory of the Centre de toxicologie du Québec. For Hg determination, blood samples were diluted 20 fold in a solution containing ammonium hydroxide before analysis. The $\mathrm{LOD}$ for $\mathrm{Hg}$ and $\mathrm{Pb}$ were $0.4 \mu \mathrm{g} / \mathrm{L}$ and $2 \mu \mathrm{g} / \mathrm{L}$ respectively; child $\mathrm{Hg}$ had four values under LOD, which were kept as measured.

For cord docosahexaenoic acid (DHA, an omega-3 fatty acid) quantification, total lipids were first extracted from a $200 \mu \mathrm{l}$ of total whole blood with $6 \mathrm{ml}$ of chloroformethanol 2:1 (v/v) containing butylated hydroxytoluene to minimize oxidation of polyunsaturated fatty acids. This method was previously validated (Chajes et al. 2008). Fatty acids were methylated with Methyl Prep II (Alltech, Templemars, France) at room temperature for 10 minutes. Fatty acids methyl esters were extracted with $4 \mathrm{ml}$ of hexane. Analyses of DHA were performed by gas chromatography (6890N Agilent, Massy France) with a capillary column (SGE, Courtaboeuf, France) used for separation of fatty acid methyl esters. DHA levels were expressed as percentage of total fatty acids by integrating the area under the peak and dividing the result by total area. Identification of DHA was made by a known mixture of fatty acid methyl esters (SUPELCO, St Quentin Fallavier, France).

\section{Confounding variables}

Sex, child age, and maternal Raven's score were treated as obligatory covariates. The following variables were considered as potential maternal and family characteristics confounders: age and parity of the mother at delivery, marital status (single or not), maternal education, family income. Child characteristics considered were gestational age and number of weeks breastfed. The presence of siblings of opposite sex was included among participant characteristics. The following contaminants and nutrients were also considered as potential confounders: cord DHA, $\mathrm{Hg}, \mathrm{Pb}, \mathrm{PCB}-153$, and DDE. 


\section{Statistical analysis}

We investigated the means, variances, and distribution of each variable. All exposure variables and maternal breastfeeding duration were $\log _{2}$-transformed to reduce skewness. An examination of the descriptive statistics and the residuals for the proportions of masculine and feminine play showed bimodal distributions and nonnormal residuals, because girls played a lot more with feminine toys and boys played a lot more with masculine toys (see Table 2). To take potential sex differences into account without splitting the sample altogether, we chose to test the association between chlordecone and sex-typed play with two-group models. In the first step, we let the parameters in each regression models vary freely between the boy group and the girl group (saturated model with 0 degrees of freedom). In a second step, we constrained to equality all corresponding parameters (beta, means, variances, covariances) between the two groups. A deterioration of the overall fit of the two-group model at this step indicates that at least one of the parameters differs significantly between boys and girls. In a third step, we allowed the means and variances to vary between boys and girls. If the overall fit was good at this step, the model was considered the most parsimonious; in cases where the fit would still be deteriorated (i.e. significantly different from the saturated model, $p<0.05)$, then we would allow the beta representing the association between the chlordecone measure and the sex-typed play outcome to vary between boys and girls to formally test the hypothesis of a moderation by sex of the contaminant-outcome association. Because of the small sample and non-normal data, we used a bootstrapping method $(\mathrm{n}=1000)$ to correct the standard errors and confidence intervals of the parameters. The proportion of missing data ranged from $0 \%$ to $25 \%$ (Child DDE; see Table 1). Little's Missing Completely at Random test (Little 1988) performed in SPSS on all contaminants measures, outcomes, and confounders, was not significant (Little's Chi-Square $=453.42, \mathrm{DF}=453, p=0.49$ ), therefore the missing data were considered unbiased. Descriptive statistics, bivariate correlations and patterns of missing data analyses were computed with IBM SPSS 25.0 for Windows (IBM, Chicago, IL, USA). All multivariate models were tested with Mplus 8.2 (Muthén and Muthén, 1998-2017).

\section{Results}

Descriptive statistics and bivariate associations

Table 1 shows that less than half of the children had a sibling of the opposite sex at home, which could affect their familiarity with sex-typed toys. Further analysis showed that girls who had brothers $(\mathrm{n}=27)$ actually played less with masculine toys (mean masculine play for girls without brothers $=0.29$; mean masculine play for girls with brothers $=0.13 ; T(67)=3.22, p=0.002)$. Contaminant exposure generally decreased between birth 
(cord blood concentrations) and childhood (7-year blood), except for Pb, which increased, and DDE, which stayed relatively stable. Boys and girls did not differ in exposure for any of the contaminants (non-significant $T$ tests not shown). Table 2 shows the proportion of time spend playing with feminine and masculine toys. As expected, boys spent largely more time playing with masculine toys ( $77 \%$ of the playing time) while girls were spending more time playing with feminine toys (68\% of the playing time).

Results from Table 3 shows that cord and child chlordecone concentrations are not significantly correlated, as well as they are not related with the other contaminants documented. Significant correlations are found between persistent organochlorine compounds PCB-153 and DDE. Cord and child Pb concentrations are significantly correlated while only child $\mathrm{Pb}$ concentrations are correlated with cord PCB-153 and cord $\mathrm{Hg}$.

Two-group models predicting sex-typed play

The unconstrained models showing the association of chlordecone exposure with masculine and feminine play for boys and girls are reported in Table 4, and the subsequent tests of model fit after constraining the parameters are shown in Table 5. We found no significant association of prenatal and childhood chlordecone exposure with masculine or feminine play, and no moderation of these associations by sex. However, the standardized beta larger than 0.20 between childhood chlordecone and feminine play in both boys and girls suggest that the lack of significance could be a power issue. In all models, constraining all parameters between boys and girls resulted in a significant deterioration of model fit (Chi-square difference between the saturated model and the constrained model at $p<0.000)$. In all cases, freeing the means and variances of the measures of sex-typed play between boys and girls resulted in models with good fit; this means that models with the same parameters for boys and girls except for the means and variance of masculine and feminine play were the most parsimonious.

\section{Discussion}

This is the first study of its kind conducted in a population environmentally exposed to chlordecone, an EDC with well-established estrogenic and progestogenic properties. Our results show no association between prenatal chlordecone exposure and the time spent playing with toys boys and girls are typically attracted to. An increase in playtime with feminine toys (feminization) was observed in association with childhood chlordecone exposure for children of both sexes, but did not reach statistical significance $(p=0.17)$.

Chlordecone blood levels observed in our population are thousand times lower than those measured among the intoxicated Hopewell workers, but similar to those experienced by a community population around 
the Hopewell factory in the 1970 's, in which $12 \%$ reported tremor symptoms compared to $46 \%$ of the workers (Cannon 1978). There is currently no data on exposure to chlordecone in other populations.

Early experimental studies in rodents have suggested sex-dependent, persistent alterations in neurobehavioral function as responses to neonatal exposure to chlordecone (Squibb \& Tilson 1982; Mactutus \& Tilson 1984; Mactutus 1985; Cooper 1985). A more recent study reported both masculinized and feminized reproductive (mounting, lordosis) and non-reproductive behaviors (exploratory behavior, anxiety) in adult rats following gestational exposure to chlordecone, consistent with both estrogenic and anti-estrogenic effects (Laessig et al. 2007), depending on the estrogen receptor subtypes that are being activated or antagonized (Lemaire et al. 2006). In previous analyses of the same TIMOUN birth cohort, reduced novelty preference was observed at 7 months in children of both sexes (Dallaire et al. 2012), and poorer fine motor function among boys at 18 months (Boucher et al. 2013) in association with increased prenatal exposure to chlordecone. These previous reports suggest a sex-dependent impact of prenatal exposure to chlordecone on child neurobehavioral development at 18 months, which is not apparent in our present report.

Several reasons may explain these negative findings. First, the small sample implies a loss of statistical power. However, effect size of prenatal exposure, in both sexes, is small (standardized beta $<0.123$ for feminine play, $<0.096$ for masculine play). Compared to the whole cohort, families engaged in the neurodevelopmental follow-up (no maternal diseases, no adverse birth outcomes) were more educated and slightly less exposed to chlordecone (as expected due to the existing association between chlordecone exposure and risk of preterm birth - Kadhel et al. 2014). Children who participated in the play session were not different from other children in the follow-up. The choice of a "healthy sample" for the investigation of possible neurodevelopmental consequences of chlordecone was justified by the high prevalence of maternal diseases during pregnancy in Guadeloupe (Rouget et al. 2013), that may have blurred the association with environmental exposure. This choice, however, limits the generalization of our results. Another potential limitation relates to the instrument used. The structured play session was adapted from a similar protocol used in the general population to study the evolution of toy preference with age (from 1 to 5 years) (Servin et al. 1999) and in clinical setting among girls with congenital adrenal hyperplasia, therefore submitted to overproduction of androgens in utero (Nordenström et al. 2002). In both situations, this protocol proved to be a very sensitive tool. Previous studies investigating the influence of prenatal exposure to PCBs/PCDDs (Vreugdenhill 2002; Winneke 2014) or of phthalates (Swan 2010) on sextyped play behavior, used the Pre-School Activities Inventory (PSAI). The PSAI is based on parental, mainly maternal, reports of a combination of aspects of sexual behavioral dimorphism along three categories, namely 
toys preference (e.g. cars vs dolls), preferred activities (e.g. rough-and-tumble vs homework play) and other characteristics (e.g. risk taking vs risk avoidance) (Golombok \& Rust 1993). Our instrument, unlike the PSAI, is based on only one of these aspects, namely direct standardized observations of toys preference. Nevertheless, we believe that our standardized play session, although representing a more narrow behavioral spectrum than the PSAI, is more objective, more specific and more adapted to the hypothesis tested. The choice of toys in the structured play session is important however. The greater proportion of time playing with toys typically designed for the child's sex somewhat validate our selection of the toys for the play session, but we had to exclude $a$ posteriori a toy that was not clearly feminine, masculine or neutral, reducing the overall time of observation. This may have reduced our ability to fully capture the outcome measured.

No human or experimental studies of the consequences of postnatal exposure to chlordecone on neurobehavior before puberty are available. In adult male rats, acute or chronic exposure to chlordecone induces neurobehavioral changes in a series of tests for sensorimotor functions (Squibb and Tilson 1982; Pryor et al. 1983). In our study, although the increase in proportion of time playing with feminine toys (feminization) in children of both sexes in association with childhood chlordecone exposure did not reach statistical significance $(p=0.17)$, the strength of the association (standardized regression coefficients $>0.20$ ) or the effect size is in the same range as those reported by Boucher et al. (2013) when measuring associations between prenatal chlordecone exposure and fine motor scores at 18 months in the same TIMOUN cohort. Therefore, additional studies with larger sample size are needed to determine whether feminization of behavior, if any, could be attributed to the progestogenic action of chlordecone (Birke and Sadler 1983; 1984). In such studies a protocol involving the objective observation of toy preference, as used in the present study, could be combined with parental reporting of more comprehensive aspects of sexual dimorphism. 


\section{References}

Alexander GM, Wilcox T, Woods R (2009) Sex Differences in Infants' Visual Interest in Toys. Arch Sex Behav 38:427-433. doi: 10.1007/s10508-008-9430-1

Bell MR (2014) Endocrine-disrupting actions of PCBs on brain development and social and reproductive behaviors. Curr Opin Pharmacol 19:134-144. doi: 10.1016/j.coph.2014.09.020

Bernert JT, Turner WE, Patterson DG, Needham LL (2007) Calculation of serum "total lipid" concentrations for the adjustment of persistent organohalogen toxicant measurements in human samples. Chemosphere 68:824-831. doi: 10.1016/j.chemosphere.2007.02.043

Birke LI, Sadler D (1983) Progestin-induced changes in play behaviour of the prepubertal rat. Physiol Behav 30:341-347. doi: 10.1016/0031-9384(83)90136-1

Birke LI, Sadler D (1984) Modification of juvenile play and other social behaviour in the rat by neonatal progestins: Further studies. Physiol Behav 33:217-219. doi: 10.1016/0031-9384(84)90102-1

Boucher O, Simard MN, Muckle G, et al (2013) Exposure to an organochlorine pesticide (chlordecone) and development of 18-month-old infants. Neurotoxicology 35:162-168. doi: 10.1016/j.neuro.2013.01.007

Caldwell BM, Bradley RH (2001) HOME Inventory and Administration Manual, $3^{\text {rd }}$ edn. University of Arkansas for Medical Sciences and University of Arkansas at Little Rock

Cannon SB, Veazey JM, Jackson, et al (1978) Epidemic kepone poisoning in chemical workers. Am J Epidemiol 107:529-537. doi: 10.1093/oxfordjournals.aje.a112572

Chajes V, Thiebaut ACM, Rotival M, et al (2008) Association between serum trans-monounsaturated fatty acids and breast cancer risk in the E3N-EPIC Study. Am J Epidemiol 167:1312-1320. doi: 10.1093/aje/kwn069

Collaer ML, Hines M (1995) Human behavioral sex differences: A role for gonadal hormones during early development? Psychol Bull 118:55-107. doi: 10.1037/0033-2909.118.1.55

Cooper JR, Vodicnik MJ, Gordon JH (1985) Effects of perinatal Kepone exposure on sexual differentiation of the rat brain. Neurotoxicology 6:183-90 
Dallaire R, Muckle G, Rouget F, et al (2012) Cognitive, visual, and motor development of 7-month-old Guadeloupean infants exposed to chlordecone. Environ Res 118:79-85. doi: 10.1016/j.envres.2012.07.006

Debier C, Pomeroy P, Dupont C, et al (2003) Quantitative dynamics of PCB transfer from mother to pup during lactation in UK grey seals Halichoerus grypus. Mar Ecol Prog Ser 247:237-248. doi: 10.3354/meps247237

Dubuisson C, Héraud F, Leblanc J-C, et al (2007) Impact of subsistence production on the management options to reduce the food exposure of the Martinican population to Chlordecone. Regul Toxicol Pharmacol 49:516. doi: 10.1016/j.yrtph.2007.04.008

Faroon O, Jones D, De Rosa C (2000) Effects of polychlorinated biphenyls on the nervous system. Toxicol Ind Health 16:305-333. doi: 10.1177/074823370001600708

Faroon O, Kueberuwa S, Smith L, Derosa C (1995) Atsdr Evaluation of Health Effects of Chemicals. Toxicol Ind Health 11:1-195. doi: 10.1177/074823379501100601

Frye C, Bo E, Calamandrei G, et al (2012) Endocrine disrupters: A review of some sources, effects, and mechanisms of actions on behaviour and neuroendocrine systems. J Neuroendocrinol 24:144-159. doi: 10.1111/j.1365-2826.2011.02229.x

Golombok S, Rust J (1993) The Pre-School Activities Inventory: A standardized assessment of gender role in children. Psychol Assess 5:131-136. doi: 10.1037/1040-3590.5.2.131

Guldner L, Multigner L, Héraud F, et al (2010) Pesticide exposure of pregnant women in Guadeloupe: Ability of a food frequency questionnaire to estimate blood concentration of chlordecone. Environ Res 110:146-151. doi: 10.1016/j.envres.2009.10.015

Guo YL, Lai TJ, Chen SJ, Hsu CC (1995) Gender-related decrease in Raven's progressive matrices scores in children prenatally exposed to polychlorinated biphenyls and related contaminants. Bull Environ Contam Toxicol 55:8-13. doi: 10.1007/BF00212382

Hammond B, Katzenellenbogen BS, Krauthammer N, McConnell J (1979) Estrogenic activity of the insecticide chlordecone (Kepone) and interaction with uterine estrogen receptors. Proc Natl Acad Sci 76:6641-6645. doi: 10.1073/pnas.76.12.6641 
Hassett JM, Siebert ER, Wallen K (2008) Sex differences in rhesus monkey toy preferences parallel those of children. Horm Behav 54:359-364. doi: 10.1016/j.yhbeh.2008.03.008

Kadhel P, Monfort C, Costet N, Rouget F, Thomé JP, Multigner L, Cordier S (2014) Chlordecone exposure, length of gestation, and risk of preterm birth. Am J Epidemiol 179:536-44. doi: 10.1093/aje/kwt313

Laessig SA, Auger AP, McCarthy MM, Silbergeld EK (2007) Effects of prenatal chlordecone on sexually differentiated behavior in adult rats. Neurotoxicol Teratol 29:255-263. doi: 10.1016/j.ntt.2006.10.003

Lemaire G, Mnif W, Mauvais P, et al (2006) Activation of $\alpha$ - and $\beta$-estrogen receptors by persistent pesticides in reporter cell lines. Life Sci 79:1160-1169. doi: 10.1016/j.1fs.2006.03.023

Little RJA (1988) A test of missing completely at random for multivariate data with missing values. J Am Stat Assoc 83:1198-1202. doi: 10.1080/01621459.1988.10478722

Lombardo M V., Ashwin E, Auyeung B, et al (2012) Fetal Testosterone Influences Sexually Dimorphic Gray Matter in the Human Brain. J Neurosci 32:674-680. doi: 10.1523/JNEUROSCI.4389-11.2012

Mactutus CF, Tilson HA (1985) Evaluation of long-term consequences in behavioral and/or neural function following neonatal chlordecone exposure. Teratology 31:177-186. doi: 10.1002/tera.1420310202

Mactutus CF, Tilson HA (1984) Neonatal chlordecone exposure impairs early learning and retention of active avoidance in the rat. Neurobehav Toxicol Teratol 6:75-83

Mactutus CF, Unger K, Tilson HA (1982) Neonatal chlordecone exposure impairs early learning and memory in the rat on a multiple passive avoidance task. Neurotoxicology 3:27-44

McCarthy MM, Arnold AP (2011) Reframing sexual differentiation of the brain. Nat Neurosci 14:677-683. doi: $10.1038 / \mathrm{nn} .2834$

Multigner L, Ndong JR, Giusti A, et al (2010) Chlordecone Exposure and Risk of Prostate Cancer. J Clin Oncol 28:3457-3462. doi: 10.1200/JCO.2009.27.2153

Multigner L, Kadhel P, Rouget F, et al (2016) Chlordecone exposure and adverse effects in French West Indies populations. Environ Sci Pollut Res Int 23:3-8. doi: 10.1007/s11356-015-4621-5 
Muthén LK and Muthén BO (1998-2017) Mplus User's Guide. 8th Edition. Los Angeles, CA: Muthén \& Muthén

Nordenström A, Servin A, Bohlin G, et al (2002) Sex-typed toy play behavior correlates with the degree of prenatal androgen exposure assessed by CYP21 genotype in girls with congenital adrenal hyperplasia. J Clin Endocrinol Metab 87:5119-5124. doi: 10.1210/jc.2001-011531

Pryor GT, Uyeno ET, Tilson HA, Mitchell CL (1983) Assessment of chemicals using a battery of neurobehavioral tests: a comparative study. Neurobehav Toxicol Teratol 5:91-117

Raven J, Raven JC, Court JH (2003). Manual for Raven's Progressive Matrices and Vocabulary Scales. Section 1: General Overview. San Antonio, TX: Harcourt Assessment.

Rouget F, Lebreton J, Kadhel P, et al (2013) Medical and sociodemographic risk factors for preterm birth in a French Caribbean population of African descent. Matern Child Health J 17:1103-11. doi: $10.1007 / \mathrm{s} 10995-012-1112-\mathrm{x}$

Schantz SL, Moshtaghian J, Ness DK (1995) Spatial learning deficits in adult rats exposed to ortho-substituted PCB congeners during gestation and lactation. Toxicol Sci. doi: 10.1093/toxsci/26.1.117

Scippo ML, Argiris C, Van De Weerdt C, et al (2004) Recombinant human estrogen, androgen and progesterone receptors for detection of potential endocrine disruptors. Anal Bioanal Chem 378:664-669. doi: $10.1007 / \mathrm{s} 00216-003-2251-0$

Servin A, Bohlin G, Berlin L (1999) Sex differences in 1-, 3-, and 5-year-olds' toy-choice in a structured playsession. Scand J Psychol 40:43-48. doi: 10.1111/1467-9450.00096

Seurin S, Rouget F, Reninger J-C, et al (2012) Dietary exposure of 18-month-old Guadeloupian toddlers to chlordecone. Regul Toxicol Pharmacol 63:471-479. doi: 10.1016/j.yrtph.2012.05.009

Squibb R, Tilson HA (1982) Effects of gestational and perinatal exposure to chlordecone (Kepone) on the neurobehavioral development of Fischer-344 rats. Neurotoxicology 3:17-26 
Swan SH, Liu F, Hines M, et al (2010) Prenatal phthalate exposure and reduced masculine play in boys. Int J Androl 33:259-267. doi: 10.1111/j.1365-2605.2009.01019.x

Templ M, Hron K, Filzmoser P (2011). RobCompositions: an R-package for robust statistical analysis of compositional data. In V. Pawlowsky-Glahn and A. Buccianti, editors, Compositional Data Analysis. Theory and Applications, pp. 341-355, John Wiley \& Sons, Chichester (UK)

Vonier PM, Crain DA, McLachlan JA, et al (1996) Interaction of environmental chemicals with the estrogen and progesterone receptors from the oviduct of the American alligator. Environ Health Perspect 104:13181322. doi: $10.1289 /$ ehp. 961041318

Vreugdenhil HJI, Slijper FME, Mulder PGH, Weisglas-Kuperus N (2002) Effects of perinatal exposure to PCBs and dioxins on play behavior in Dutch children at school age. Environ Health Perspect 110:593-598. doi: sc271_5_1835[pii]

Winneke G, Ranft U, Wittsiepe J, et al (2014) Behavioral sexual dimorphism in school-age children and early developmental exposure to dioxins and PCBs: A follow-up study of the duisburg cohort. Environ Health Perspect 122:292-298. doi: 10.1289/ehp.1306533 
Table 1. Characteristics of study participants $(N=116)$

\begin{tabular}{|c|c|c|c|c|c|}
\hline Variables & $\overline{\mathbf{N}}$ & $\%$ & Mean \pm SD & Median & Range \\
\hline \multicolumn{6}{|l|}{ Family and pregnancy characteristics } \\
\hline Maternal age at delivery (years) & 116 & & $30.9 \pm 6.3$ & 32.1 & $17-43$ \\
\hline Maternal education & 116 & & & & \\
\hline Primary or none & & 4.3 & & & \\
\hline High school & & 44.0 & & & \\
\hline Some college or higher degree & & 51.7 & & & \\
\hline Maternal RAVEN score & 114 & & $36.7 \pm 12.9$ & 39.0 & $10.0-57.0$ \\
\hline Marital status (\% living with partner) & 116 & 67.2 & & & \\
\hline Family income (per month) & 114 & & & & \\
\hline$\leq 1500$ euros & & 35.1 & & & \\
\hline $1501-3000$ euros & & 36.8 & & & \\
\hline$\geq 3001$ euros & & 28.1 & & & \\
\hline Parity before child birth & 116 & & & & \\
\hline 0 & & 44.0 & & & \\
\hline $1-2$ & & 44.0 & & & \\
\hline$\geq 3$ & & 12.1 & & & \\
\hline \multicolumn{6}{|l|}{ Child characteristics } \\
\hline Sex $(\%$ female $)$ & 116 & 53.4 & & & \\
\hline Birth weight $(\mathrm{g})$ & 116 & & $3305 \pm 381$ & 3260 & $2570-4350$ \\
\hline Gestational age (weeks) & 116 & & $39.0 \pm 1.1$ & 39.0 & $37-41$ \\
\hline Age at visit (years) & 116 & & $7.7 \pm 0.2$ & 7.7 & $7.2-8.0$ \\
\hline Breastfeeding duration (months) & 115 & & $10.0 \pm 11.3$ & 6.0 & $0-48.0$ \\
\hline$<3$ & & 22.6 & & & \\
\hline $3-6$ & & 32.2 & & & \\
\hline$>6$ & & 45.2 & & & \\
\hline Presence of siblings of opposite sex (\%) & 116 & 40.5 & & & \\
\hline HOME total score at 18 -months old visit & 95 & & $32.8 \pm 5.4$ & 33.0 & $16.0-42.0$ \\
\hline \multicolumn{6}{|l|}{ Prenatal exposures } \\
\hline Tobacco during pregnancy ( $\%$ yes) & 116 & 5.2 & & & \\
\hline Alcohol during pregnancy (\% yes) & 113 & 5.3 & & & \\
\hline Cord chlordecone $(\mu \mathrm{g} / \mathrm{L})^{a}$ & 104 & & $0.1 \pm 5.8$ & 0.17 & $<\mathrm{LOD}-7.4$ \\
\hline$\%$ Detected & & 70.2 & & & \\
\hline Cord PCB-153 $(\mu \mathrm{g} / \mathrm{L})^{a}$ & 108 & & $0.8 \pm 3.1$ & 0.1 & $<$ LOD -0.7 \\
\hline
\end{tabular}




\begin{tabular}{|c|c|c|c|c|}
\hline$\%$ Detected & & & & \\
\hline Cord DDE $(\mu \mathrm{g} / \mathrm{L})^{a}$ & 108 & $0.3 \pm 1.4$ & 0.3 & $<\mathrm{LOD}-11.3$ \\
\hline$\%$ Detected & & & & \\
\hline Cord $\mathrm{Hg}(\mu \mathrm{g} / \mathrm{L})^{a}$ & 111 & $6.3 \pm 1.8$ & 6.6 & $1.5-34.1$ \\
\hline$\%$ Detected & & & & \\
\hline Cord $\mathrm{Pb}(\mu \mathrm{g} / \mathrm{L})^{a}$ & 111 & $14.3 \pm 1.6$ & 13.5 & $5.2-99.5$ \\
\hline$\%$ Detected & & & & \\
\hline Cord DHA (\% total phospholipids) ${ }^{a}$ & 104 & $3.9 \pm 1.5$ & 3.9 & $1.4-10.0$ \\
\hline$\%$ Detected & & & & \\
\hline \multicolumn{5}{|c|}{ Childhood exposures (7-year follow-up) } \\
\hline Child chlordecone $^{a}$ & 89 & $0.04 \pm 3.2$ & 0.0 & $<\mathrm{LOD}-1.0$ \\
\hline$\%$ Detected & & & & \\
\hline Child PCB-153 $(\mu \mathrm{g} / \mathrm{L})^{a}$ & 88 & $0.1 \pm 2.4$ & 1 & $<\mathrm{LOD}-1.0$ \\
\hline$\%$ Detected & & & & \\
\hline Child DDE $(\mu \mathrm{g} / \mathrm{L})^{a}$ & 87 & $0.3 \pm 3.5$ & 0.2 & $<\mathrm{LOD}-26.4$ \\
\hline \multicolumn{5}{|l|}{$\%$ Detected } \\
\hline Child Hg $(\mu \mathrm{g} / \mathrm{L})^{a}$ & 89 & $1.7 \pm 2.2$ & 1.8 & $<$ LOD- 12.2 \\
\hline$\%$ Detected & & & & \\
\hline Child $\mathrm{Pb}(\mu \mathrm{g} / \mathrm{L})^{a}$ & 89 & $22.6 \pm 1.5$ & 23.2 & $8.1-75.2$ \\
\hline$\%$ Detected & & & & \\
\hline
\end{tabular}

${ }^{a}$ Geometric mean \pm geometric standard deviation calculated on all values, including the imputed ones.

Abbreviations: Maternal RAVEN score, Raven's Progressive Matrices continuous score (Raven et al. 1992); HOME, Home Observation for Measurement of the Environment (Caldwell and Bradley, 2001); PCB 153, polychlorinated biphenyl congener 153; DDE, $p$, $p$ 'dichlorodiphenyl dichloroethylene; $\mathrm{Hg}$, mercury; $\mathrm{Pb}$, lead; $\mathrm{DHA}$, docosahexaenoic acids; 
Table 2- Play descriptive statistics by sex

\begin{tabular}{|c|c|c|c|c|c|}
\hline & Boys & & & Girls & \\
\hline Mean $\pm \mathrm{SD}$ & Median & Range & Mean $\pm \mathrm{SD}$ & Median & Range \\
\hline $0.08 \pm 0.14$ & 0.00 & $0.00-0.68$ & $0.60 \pm 0.33$ & 0.68 & $0.00-1.00$ \\
\hline $0.77 \pm 0.28$ & 0.89 & $0.00-1.00$ & $0.21 \pm 0.22$ & 0.12 & $0.00-0.78$ \\
\hline
\end{tabular}

Note: SD, standard deviation 
Table 3- Pearson correlations ( $p$-value) between contaminants blood concentrations

\begin{tabular}{|c|c|c|c|c|c|c|c|c|c|}
\hline & \multicolumn{5}{|c|}{ Cord } & \multicolumn{4}{|c|}{ Child } \\
\hline & Chlordecone & PCB-153 & DDE & $\mathrm{Hg}$ & $\mathrm{Pb}$ & Chlordecone & PCB-153 & DDE & $\mathrm{Hg}$ \\
\hline \multicolumn{10}{|l|}{ Cord } \\
\hline PCB-153 & $0.07(0.47)$ & - & & & & & & & \\
\hline DDE & $0.15(0.13)$ & $-0.09(0.35)$ & - & & & & & & \\
\hline $\mathrm{Hg}$ & $-0.07(0.49)$ & $0.04(0.69)$ & $0.01(0.89)$ & - & & & & & \\
\hline $\mathrm{Pb}$ & $0.05(0.64)$ & $-0.06(0.52)$ & $0.13(0.2)$ & $0.004(0.97)$ & - & & & & \\
\hline \multicolumn{10}{|l|}{ Child } \\
\hline Chlordecone & $0.19(0.10)$ & $0.01(0.94)$ & $0.08(0.51)$ & $0.20(0.07)$ & $0.09(0.41)$ & - & & & \\
\hline PCB- 153 & $-0.06(0.60)$ & $-0.23(0.04)$ & $0.29(0.01)$ & $0.08(0.46)$ & $0.003(0.98)$ & $-0.10(0.37)$ & - & & \\
\hline DDE & $0.01(0.95)$ & $-0.30(0.01)$ & $0.54(0.00)$ & $0.005(0.97)$ & $0.20(0.07)$ & $0.08(0.48)$ & $0.55(0.00)$ & - & \\
\hline $\mathrm{Hg}$ & $0.02(0.90)$ & $-0.02(0.84)$ & $-0.005(0.97)$ & $0.12(0.28)$ & $-0.08(0.48)$ & $0.05(0.62)$ & $0.05(0.65)$ & $0.14(0.18)$ & - \\
\hline $\mathrm{Pb}$ & $-0.06(0.63)$ & $-0.28(0.01)$ & $0.10(0.35)$ & $-0.19(0.09)$ & $0.23(0.03)$ & $-0.08(0.44)$ & $0.14(0.21)$ & $0.08(0.47)$ & $-0.28(0.007)$ \\
\hline
\end{tabular}

Note: PCB 153, polychlorinated biphenyl congener 153; DDE, $p, p^{\prime}$-dichlorodiphenyl dichloroethylene; $\mathrm{Hg}$, mercury; Pb, lead;

All measures log-2 transformed.

Sample size for individual comparisons varies between 76 and 108 due to missing values. 
Table 4- Associations of contaminants with female and male play for boys and girls

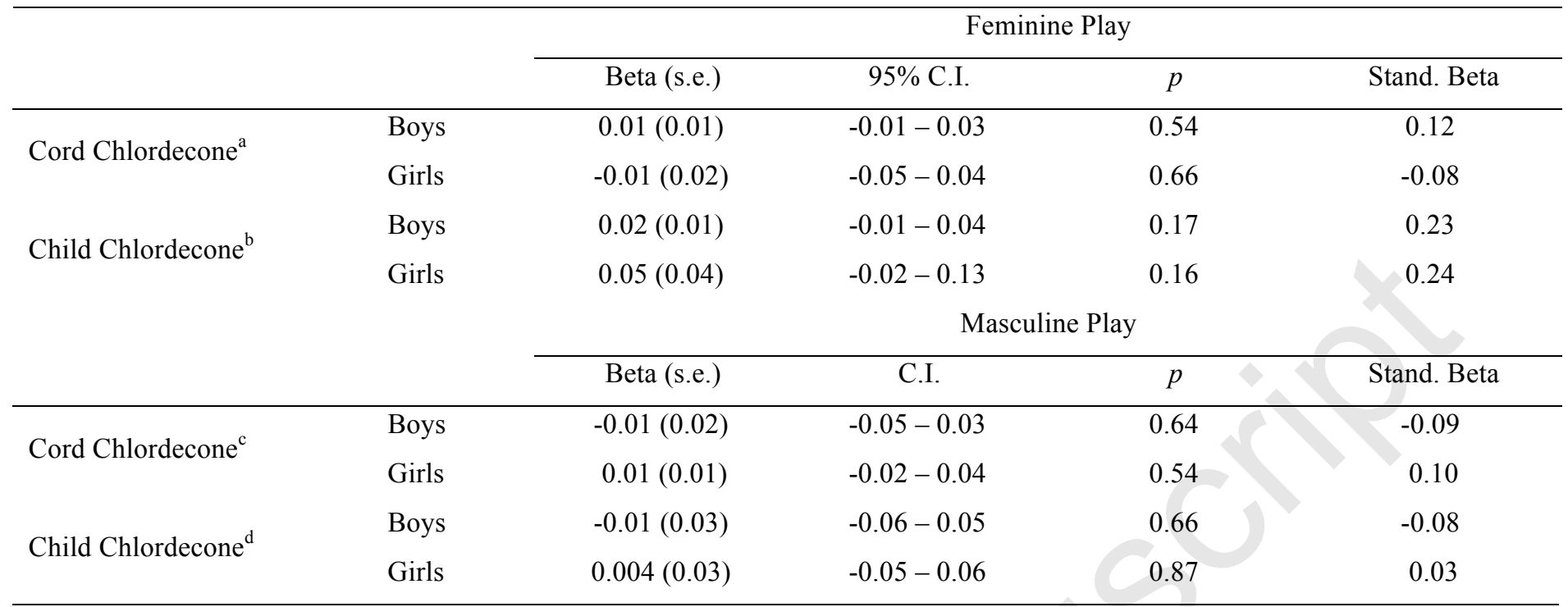

Note: Two-group regression models tested with an FIML estimator. Standard errors and confidence intervals obtained by bootstrapping $(\mathrm{n}=1000)$. All models are adjusted for age at testing and mother's Raven score. Additional confounding factors: ${ }^{\mathrm{a} C o r d}$ Hg, child PCB 153, child total lipid; ${ }^{b}$ Child PCB 153, child total lipid; ${ }^{\mathrm{c}} \mathrm{Cord} \mathrm{Hg}$, presence of siblings of opposite sex; ${ }^{\mathrm{d}}$ Mother's marital status (living with partner or not). 
Table 5- Changes in model fits in the sex X contaminants interaction tests

\begin{tabular}{|c|c|c|c|c|}
\hline & & \multicolumn{3}{|c|}{ Feminine Play } \\
\hline & & $X^{2}$ & $\mathrm{DF}$ & $p$ \\
\hline \multirow{3}{*}{ Cord Chlordecone } & Constrained model & 130.86 & 20 & 0.00 \\
\hline & $\begin{array}{l}\text { Mean/variance parameters of play } \\
\text { freed }\end{array}$ & 14.40 & 18 & 0.70 \\
\hline & Constrained model & 134.21 & 17 & 0.00 \\
\hline \multirow[t]{3}{*}{ Child Chlordecone } & $\begin{array}{l}\text { Mean/variance parameters of play } \\
\text { freed }\end{array}$ & 14.90 & 15 & 0.46 \\
\hline & & $X^{2}$ & $\mathrm{DF}$ & $p$ \\
\hline & Constrained model & 126.77 & 27 & 0.00 \\
\hline Cord Chlordecone & $\begin{array}{l}\text { Mean/variance parameters of play } \\
\text { freed }\end{array}$ & 25.07 & 25 & 0.46 \\
\hline & Constrained model & 116.50 & 20 & 0.00 \\
\hline Child Chlordecone & $\begin{array}{l}\text { Mean/variance parameters of play } \\
\text { freed }\end{array}$ & 20.15 & 18 & 0.33 \\
\hline
\end{tabular}

Note: Constrained model $=$ all parameters constrained to equality in the two groups (boys and girls). Significant $p$ indicates a deterioration of the model fit caused by the constraint. Mean/variance parameters of play freed = the equality constraint between the groups was relaxed for the mean and variance of male play and female play. Non-significant $p$ indicates that the relaxed model shows a good fit to the data. 